\title{
Evaluating Ecological Tourism under Sustainable Development in Karst Area
}

\author{
Zhou You \\ School of Economics \& Management, University of Sichuan Agriculture \\ 46 Xin Kang Road, Ya'an 625014, China \\ Tel: 86-187-2816-7078 E-mail:Zhouyou546517129@126.com \\ Wenkuan Chen (Corresponding author) \\ School of Economics \& Management, University of Sichuan Agriculture \\ 46 Xin Kang Road, Ya'an 625014, China \\ Tel: 86-139-8017-9889 E-mail: cwk9889 @ yahoo.com.cn
}

Liu Song

School of Economics \& Management, University of Sichuan Agriculture 46 Xin Kang Road, Ya'an 625014, China

Tel: 86-138-8244-6030Ｅ-mail:songliu1987@163.com

Received: November 26, 2010

Accepted: December 20, 2010

doi:10.5539/jsd.v4n2p234

The research is financed by Sponsors: Modern ecological agriculture planning in Southwest (CR1002)

\begin{abstract}
Sustainable ecological tourism is the ultimate goal of ecological tourism. To realize the sustainable development of ecological tourism it is a thorny problem. This paper takes the world geological park in Xinwen for evaluation object, according to the sustainable development of ecological tourism evaluation model, using analytic hierarchy process, expert evaluation method, the multi-objective linear weighted function method and relevant data, establishing the sustainable development of ecological tourism evaluation index system and evaluation model. Then the index system and evaluation model can be used to evaluate the level of the sustainable development of area's ecological tourism, and it belongs to the preparation stage in the sustainable development of ecological tourism. Finally, according to the results of the evaluation, put forward some countermeasures to improve the world geological park in Xinwen on the sustainable development of ecological tourism.
\end{abstract}

Keywords: Ecological tourism, Sustainable Development, AHP Law, Karst area

With the development of economy, the tourism industry becomes one of the world's pillar industries. With the development of the tourism, it's also bringing a lot of problems, such as tourism resource excessive development, tourism management backward, and the ecological environment quality is becoming more and more worse, which is a serious threat to the sustainable development of tourism industry. In this context, many visitors start paying attention to return to the natural ecological tourism (Liu Jiaming, 1998, pp.327-331). Because our country citizen's awareness of the environment and the average level of culture both need to be improved, Ecological tourist groups have not formed in China; Most of the scenic spots plan and design their products According to the public demand; Under the banner of "ecological tourism" but they don't know what is the real ecological tourism. And don't know how to design and management of ecological tourism scenic spot (Li Donghe, 1995, pp. 75-79).

Ecological tourism either in theory or in practice is confused. Although the ecological tourism accounts for only a small part of tourism industry, but it is very important especially in the environmentally fragile areas and the culture sensitive areas, And in the eco-tourism development process, there is still a degree of unsustainable. so the ecotourism scenic spot to evaluate becomes necessary. 


\section{General situation of the studying area}

The world geological park in Xinwen is located in Sichuan basin and the transition zone of Yunnan plateau, Belongs to the southern edge of Sichuan basin of Karst-gorge- high mountain landforms types. The total area of the park is 156 Square kilometers; it is a highly regional characteristic of Karst-natural complex (Zeng Yong, 1991, pp.38-45). There are rich and various types of geological relics, Especially in Karst geological landscapes of various forms of typical and uniqueness. There are the important meanings of the landscape such as "The earth super-large funnel", "Largest rocky sea in China" and "longest visit cave in China" which are famous all over the world. On January 19, 2004, it's approved for the national geological park by Ministry of land resources. Then On February 11, 2005, it has become the second batch of the world geological park by UNESCO in formal approval, it's the first world geological park in Sichuan (Wen Tao, 2006, pp.142-145). The world geological park in Xinwen locates on the basis of southwest tourism circle, Peripheral traveling resources are rich, and influence and radiation are wide (Wen Tao, 2007, pp.21-22).

\section{Evaluation process}

\subsection{Evaluation system construction and the index weight calculation}

The paper established evaluation index system according to the sustainable development of ecological tourism evaluation method, and with scientific, integrity, operability, leading, level-oriented, dynamic, stability, focus for principle (Yan Shougang, 2007, pp.193; Peng Lisheng, 2006, pp, 177-180).

In accordance with the "society - economy - environment" three-component model of sustainable development, we propose three-component framework model for evaluation index system of eco-tourism sustainable development. According to the definition of eco-tourism and the evaluation index system of frame model and the national standard-- Tourism resources classification, investigation and evaluation (GB/T 18972 - 2003), and in the comprehensive consideration of the environmental protection and social progress, Following the principle of index system construction. Put forward the sustainable development of ecological tourism evaluation index system, it's a total of 37 indexes including the environmental aspect, economic aspect and social aspect. Based on the judgment of the importance degree of each indicator from experts, we establish the matrix, process comparison and marking hierarchically. Based on the analytic hierarchy process (ahp) and collecting the judgment of experts, then the 11 judgment matrix is constructed.

According to the importance of various factors, they will be divided into five categories: 1, 3,5,7,9. 1 just means two factors are equally important; 3 means one factor is an important than another; 5 means more important, 7 means very important; and 9 means absolutely important.

Solve the biggest characteristic root and the eigenvectors of the matrix, normalized and to validate the consistency. When the $\mathrm{Cr}$ is smaller than 0.10 , consider the sorting weight results with satisfactory consistency. Put the sorting of hierarchical single data obtained by the upper to lower layered order calculation, and then get the relative weight of lowest hierarchy elements. (Figure land Table 1).

\subsection{Calculation}

In accordance with the national standard--Tourism resources classification, investigation and evaluation (GB/T18972-2003), each evaluation factors will be divided into four grades, separately100-80 points, $70-50$ points,49-30 points,29-0 points. According to the expert advice, each index has selected experts scoring average arithmetic; calculate evaluation score by using multi-objective linear weighted function method.

Adopt multi-objective linear weighted function method to establish ecological tourism sustainable development evaluation model.

$$
\boldsymbol{S}=\sum_{h=1}^{p}\left[\sum_{j=1}^{m}\left(\sum_{i=1}^{n} A_{i} B_{i}\right) C_{j}\right] D_{h}
$$

According to the relevant data and expert advice, Ecological tourism sustainable development is divided into several stages, also the process of ecological tourism sustainable development can be divided into different stages of the operation target, and it is in favor of evaluation. It can find the improved approach for the ecotourism scenic spot (Table2).

Calculated after: $\mathrm{S}=33.2837+4.4988+12.1024=49.8849$ 


\section{Results and the analysis}

\subsection{Results}

It can be seen by calculating results (Table3). The sustainable development of ecological tourism level is in the later stage of preparation in the area.

\subsection{Evaluation and Analysis}

First from the perspective of resources and environment, the area is abundant landscape resources. Because be influenced by the rocky desertification of Karst landform, that is biological resources and number of species commonly relatively. The biological resources are shortage and the relatively small number of species. But this area has large brachiopods, gill and a double ventral of fossils, and still has quite famous "storm rock". So Build a world-class resource entities. Area has high expedition, ecological value. The scenic sightseeing is for more than 300 days, the scenic spot has the praise from $75 \%$ of the tourist and the most professional. The independence of the tourism resources and dimension belong to single medium level. Single structure and density of the collection of tourism resources are harmonious and good. Natural scene and humanism activity occurred periodically.

Secondly from the perspective of social-environmental quality of ecotourism, the government gives the ecotourism greatly support. The whole society Style is better. Tourism investment diversification is higher, Infrastructure construction and design should reduce the influence of local natural ecological environment.

Thirdly from the Angles of the facility construction, the operation, the management, the environmental-social benefits of the ecotourism, the scenic transportation is convenient. Tour line layout is reasonable. The basic facilities are complete. The guide signs are evident. It also has environmental education facilities. However, attach importance to the construction of environmental protection facilities, but badly implement, open-air cumulate castoff can be seen everywhere, the ecological environment are polluted, give large negative impact on the ecological landscape. Operators' environmental consciousness with economic benefit is light, enough attention did not pay to the ecological environmental impact, and their improvement measures are not timely. Formulate plan mainly from the Angle of profit, the attention to the cultural communication for tourists and protection of tourist resources is seriously not enough. The consideration of choosing and demonstrating the Ecological tourist scenic is not sufficient, mainly considering attraction of scenic. Choosing and demonstrating the Ecological tourist scenic are not reasonable, only mainly considering the attraction of scenic. The area has tourism management system, but the content of ecological management reflects less, and it is lack pertinence. The monitoring functions, managers could only process routine monitoring of fire, insect pest etc in tourism zones; They have a certain capacity for coordination, and have a strong dependence to their superiors and the government when coordinating; They do analysis after the general coping project, and then improve the measures without pertinence. Eco-tourism has an impact on the local ecological environment, but fortunately, the biodiversity could still remain unchanged. A certain degree of tourism receipts can be acquired from eco-tourism, and thus it can provide some additional funds for the protection and development of the tourist areas. Moreover, the local community residents could get a certain income through it, and so eco-tourism revenue has become a supplement of residents' total income.

From the tourist and social harmony degree Angle to analyze, 80 percent of tourists and 80 percent of residents on the tourist region satisfied, Ecological tourism and the local ethnic culture are coordination. But the tourism resources utilization ratio is less than 60 percent.

\section{Countermeasures and Suggestions}

Through the ecotourism scenic evaluation of the sustainable development in this area, in line with from actual conditions, from the principle of scenic spot management, practitioners, government in eco-tourism sustainable development put forward the following Suggestions:

\section{1 follow the principle of ecology eco-tourism development planning formulated, constructing perfect ecotourism authentication system}

Ecological tourism resources exploitation correct spelling in moderate development, the development of those which do not affect or less influence ecological resources traveling project. Nature reserve and the forest park development should take ecotourism development primarily; to protect natural balance of ecosystem, especially in the vulnerable ecological tourism resource development with the more should put ecosystem balance and environmental protection in the first consideration. In addition, the development of ecological tourism resources should also around with social and ecological environment, to keep the coordinated appreciate atmosphere in protecting resources, also increased while attract tourists charm. The world geological park in Xinwen has 
relatively rich eco-tourism resources; in order to better development and protection of ecological resources, establish a perfect eco-tourism development plan and construct a perfect ecotourism authentication system has a looming. Through establishing ecological tourism development planning in order to find a suitable scenic road of development, prevent excessive sex and the excessive development; protect the landscape diversity and biodiversity. Through the ecological tourism knowledge system can better evaluate tourism ecological resources whether to conform to the standards of ecological tourism resources. Better constraint visitors' behavior, and protect the ecological environment, can better regulate ecological tourism destinations in the planning and management schemes to meet on the ecological environment impact minimization principle. Ensuring environmental quality is not pronounced change, control in environmental self-repairing ability within the boundaries.

\subsection{To strengthen the training of professional employees, improve service quality}

Personnel engaged in tourism quality obviously largely become Xinwen eco-tourism products in-depth development of a decisive factor. Should travel from personnel team professional quality construction rose to a new understanding of height. Through the training of personnel engaged in tourism, and improve their comprehensive quality, execute tourism practitioners posts system, strengthening practitioners biology, ecology, environment and other aspects knowledge training, improve their professional morals sentiment, with their own practical action infection tourists, positively absorbs highly educated personnel enrich tourism team, invites the outstanding professional leading practitioners to carry on the practice, so as to improve tourist service quality, make the Xinwen ecological tourism get bigger development.

4.3 Reasonably solve the development and the protection, and the contradiction between the distributions of interests.

To display the natural resources reserve in protecting biodiversity, climate regulation, culture and leisure, popular science education aspects of function, the government should formulate the relevant policies and regulations strictly to natural ecological environment protection, such as establishing nature reserves, etc. The local government and tourism investors, operators such enterprise also should pass local policies and tourism planning approaches such as increasing the environmental protection. In addition, should attach great importance on the residents' interests, ensure residents ecological compensation benefits, avoid benefit imbalance. Reasonable solution tourism development and environmental protection, distribution of interests' contradiction of ecological tourism in this area, make a sustainable development.

\section{References}

Li Donghe. (1995). On the concept of eco-tourism and the rise of real. Geography and Territorial Research. 1995, 15(2):75-79.

Liu Jiaming. (1998). Advances In ecotourism and its planning research. Chinese Journal of Applied Ecology. 1998.9 (3): 327 -331.

Peng Lisheng. (2006). Application Research into the Analytic Hierarchy Pricess on Ecological Tourism Resource Assessment. Environmental Science and management. 2006 (03):177-180.

Wen Tao. (2007). Classification of tourism resources in Xingwen world geological park. Yibin Technology, 2007: 21-22.

Wen Tao. (2006). Geological landscape of the vulnerability trend in Xingwen world geological park. Environmental Science and Management, 2006.12 (9):142-145.

Yan Shougang. (2007). Eco-tourism sustainable development indicators and evaluation models. Group Economy. 2007:193

Zeng Yong. (1991). Sichuan Xingwen barrier coast of Changxing system of the ancient community structure model. China University of Mining Technology. 1991.6 (2): 38-45 
Table 1. Sustainable Development of Ecotourism total weight of evaluation index system of order

\begin{tabular}{|c|c|c|c|}
\hline $\begin{array}{l}\text { Index } \\
\text { layer }\end{array}$ & $\begin{array}{c}\text { Essential } \\
\text { Layer }(A i)\end{array}$ & $\begin{array}{c}\text { Total } \\
\text { sequencing } \\
\text { weight }\left(B_{i}\right)\end{array}$ & score \\
\hline \multirow{7}{*}{$\begin{array}{l}\text { resources quality of } \\
\text { ecotourism }\end{array}$} & landscape diversity & 0.0591 & 57.5 \\
\hline & biological diversity & 0.0591 & 48.5 \\
\hline & ecological value & 0.1590 & 57.5 \\
\hline & cherish degree & 0.0591 & 86.6 \\
\hline & scale and abundance & 0.1590 & 41.5 \\
\hline & reputation & 0.0230 & 40 \\
\hline & honeymoon period of tourist climate & 0.0126 & 80 \\
\hline \multirow{4}{*}{$\begin{array}{l}\text { social-environmental } \\
\text { quality of ecotourism }\end{array}$} & infrastructure conditions & 0.0553 & 50 \\
\hline & global features of society & 0.0082 & 34 \\
\hline & the government support for ecological tourism & 0.0213 & 72.5 \\
\hline & the diversification of investment for tourism & 0.0213 & 32.5 \\
\hline \multirow{7}{*}{$\begin{array}{l}\text { facility construction of } \\
\text { ecotourism }\end{array}$} & understand sex & 0.0067 & 40 \\
\hline & tourist facilities construction & 0.0067 & 54 \\
\hline & environmental education construction & 0.0029 & 57.5 \\
\hline & service facilities construction & 0.0067 & 63.5 \\
\hline & environmental protection facilities construction & 0.0185 & 37.5 \\
\hline & tourist facilities construction & 0.0185 & 50 \\
\hline & the capability of waste treatment & 0.0185 & 26 \\
\hline \multirow{5}{*}{$\begin{array}{l}\text { operation of } \\
\text { ecotourism }\end{array}$} & $\begin{array}{c}\text { environmental awareness of the operator } \\
\text { operation principle }\end{array}$ & 0.0095 & 44 \\
\hline & $\begin{array}{c}\text { orientation of the operator to the layout of } \\
\text { landscapes }\end{array}$ & 0.0095 & 40 \\
\hline & $\begin{array}{l}\text { the operator listen to opinions from experts, } \\
\text { protection organization, the local community and }\end{array}$ & 0.0020 & 39.5 \\
\hline & tourists & 0.0042 & 62.5 \\
\hline & the establish situation of management system & 0.0010 & 39 \\
\hline \multirow{5}{*}{$\begin{array}{l}\text { ecotourism } \\
\text { management }\end{array}$} & Monitoring and analysis of environment & 0.0093 & 35.5 \\
\hline & delimiting tourism spot environs & 0.0015 & 39 \\
\hline & supervision function & 0.0093 & 37.5 \\
\hline & coordination function & 0.0035 & 39 \\
\hline & post project analytical ability & 0.0035 & 41.5 \\
\hline \multirow{5}{*}{$\begin{array}{l}\text { environmental-social } \\
\text { benefits of ecology }\end{array}$} & $\begin{array}{l}\text { the influence of ecological tourism to the local } \\
\text { ecological environment }\end{array}$ & 0.0599 & 64 \\
\hline & the influence of ecological diversity & 00599 & 335 \\
\hline & the promotion level of passengers and residents' & 0.0261 & 32.5 \\
\hline & $\begin{array}{l}\text { environmental consciousness } \\
\text { the tourist income condition }\end{array}$ & 0.0063 & 37.5 \\
\hline & $\begin{array}{l}\text { the situation of per capita income of ecological } \\
\text { tourism for community residents }\end{array}$ & 0.0124 & 39 \\
\hline \multirow{4}{*}{$\begin{array}{c}\text { homonym between } \\
\text { environment and } \\
\text { society }\end{array}$} & the tourism degree of satisfaction & 0.0052 & 52.5 \\
\hline & the residents' degree of satisfaction & 0.0134 & 51.5 \\
\hline & the harmony of ecological tourist and local culture & 0.0347 & 47 \\
\hline & tourism resource utilization strength & 0.0134 & 81 \\
\hline
\end{tabular}


Table 2. the eco-tourism sustainable development scores of Xingwen

\begin{tabular}{llll}
\hline rule layer $\left(D_{h}\right)$ & score & \multicolumn{1}{c}{ Index layer $\left(C_{j}\right)$} & score \\
\hline environment & 33.2837 & $\begin{array}{l}\text { resources quality of ecotourism } \\
\text { social-environmental quality of } \\
\text { ecotourism }\end{array}$ & 84.013 \\
\hline Economy & 4.4988 & $\begin{array}{l}\text { the facility construction of } \\
\text { ecotourism } \\
\text { the operation of ecotourism }\end{array}$ & 31.7301 \\
& 12.1024 & $\begin{array}{l}\text { ecotourism management } \\
\text { the environmental-social benefits } \\
\text { of ecology } \\
\text { homonym between environment } \\
\text { and society }\end{array}$ & 14.28 .6679 \\
\hline
\end{tabular}

Table 3. Appraisal table of Sustainable Development of Ecotourism Standard

\begin{tabular}{ccccccc}
\hline $\begin{array}{c}\text { the synthetic } \\
\text { appraisal } \\
\text { value }\end{array}$ & $\leq 20$ & $21-35$ & $36-50$ & $51-69$ & $70-85$ & $\geq 86$ \\
(score) & & & & & & \\
\hline $\begin{array}{c}\text { evaluation } \\
\text { criterion }\end{array}$ & $\begin{array}{c}\text { preparation } \\
\text { stage }\end{array}$ & $\begin{array}{c}\text { middle } \\
\text { preparatory } \\
\text { stage }\end{array}$ & $\begin{array}{c}\text { later } \\
\text { preparatory } \\
\text { stage }\end{array}$ & $\begin{array}{c}\text { preliminary } \\
\text { stage }\end{array}$ & basic stage & $\begin{array}{c}\text { sustainable } \\
\text { development }\end{array}$ \\
\hline
\end{tabular}

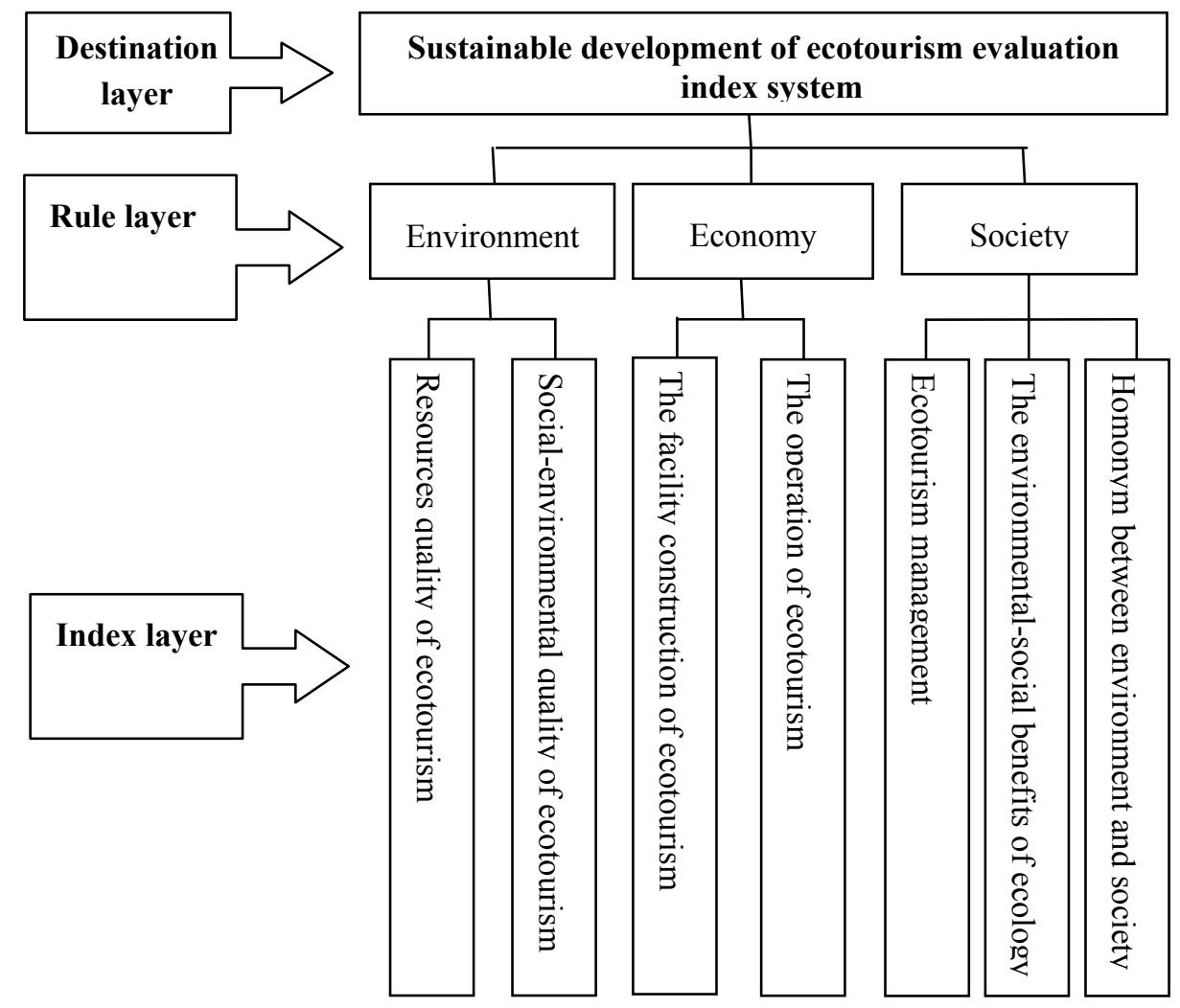

Figure 1. Sustainable Development of Ecotourism total weight of evaluation index system of order 